\title{
Wind Waves in the Arctic Seas: Envisat and AltiKa Data Analysis
}

\author{
Golubkin Pavel A. ${ }^{1,{ }^{*}}$, Chapron Bertrand ${ }^{1,2}$, Kudryavtsev Vladimir N. ${ }^{1}$ \\ ${ }^{1}$ Russian State Hydrometeorol Univ, Satellite Oceanog Lab, St Petersburg 195196, Russia. \\ ${ }^{2}$ Inst Francais Rech Exploitat Mer, Lab Oceanog Spatialee, Plouzane, France. \\ * Corresponding author : Pavel A. Golubkin, email address : pgolubkin@rshu.ru
}

\begin{abstract}
:
Wind-generated waves in the Kara, Laptev, and East-Siberian Seas are investigated using altimeter data from Envisat RA-2 and SARAL-AltiKa. Only isolated ice-free zones had been selected for analysis. Wind seas can be treated as pure wind-generated waves without any contamination by ambient swell. Such zones were identified using ice concentration data from microwave radiometers. Altimeter data, both significant wave height (SWH) and wind speed, for these areas were further obtained for the period 2002-2012 using Envisat RA-2 measurements, and for 2013 using SARAL-AltiKa. Dependencies of dimensionless SWH and wavelength on dimensionless wave generation spatial scale are compared to known empirical dependencies for fetch-limited wind wave development. We further check sensitivity of $\mathrm{Ka}-$ and Ku-band and discuss new possibilities that AltiKa's higher resolution can open.
\end{abstract}

Keywords : Altimetry, remote sensing, satellite altimeter, significant wave height, wind speed 


\section{Introduction}

Especially evident over the last 10 years, the Arctic sea ice extent can significantly drop during the summer seasons. The total extent in 2007 was reported to correspond to $76 \%$ of the previous minima recorded in the satellite era (Comiso et al. 2008). In 2012, the ice coverage was even lower (Parkinson and Comiso 2013). Such a decreasing Arctic sea ice extent may certainly provide new opportunities for maritime activities. But an increased role of wind waves in the Arctic can also be anticipated, mainly associated with modified open water fetches (Asplin et al. 2012). Rising wave heights and periods shall be expected to become a major concern for offshore platforms and coastal structures which may suffer from direct exposure or by means of coastal erosion. Moreover, wave-enhanced sea ice erosion associated with severe storms can further erode the ice margins to induce a cumulative positive feedback effect (Parkinson and Comiso 2013).

In that context, the SARAL-AltiKa instrument offers some unique opportunities to provide more detailed analysis of short fetch wave development. Indeed, operating at a higher frequency, this first Ka-band altimeter instrument has an improved spatial and height resolution (Verron et al. 2014). This instrument can thus help estimate lower values for the significant wave height parameter to more precisely examine wind wave growth in small Arctic seas, i.e. Kara, Laptev and East-Siberian Seas, as well as to inspect dependencies on open water area. Compared to more standard Ku-band altimeter observations, the SARALAltiKa radar cross section (backscatter) measurements can further be analyzed to evaluate the expected improved sensitivity of Ka-band signals to sea surface roughness changes.

In this paper, we will report on some first results using SARAL-AltiKa to discuss these different aspects. 


\section{Data and methods}

We concentrate our analysis on areas fully enclosed by sea ice and coast lines to best eliminate possible swell influence. Such zones were identified using ice concentration data provided by National Snow \& Ice Data Center (http://nsidc.org), derived from brightness temperatures measured by satellite microwave radiometers Special Sensor Microwave Imager (SSM/I) and Special Sensor Microwave Imager Sounder (SSMIS) onboard Defense Meteorological Satellite Program (DMSP) satellites F13 and F17, respectively. Figure 1 represents an example of our area of interest on June 18th, 2013 with three ice-free regions (two in Laptev Sea, one in Kara Sea). The significant wave heights (SWH) for the corresponding date are plotted.

SWH, normalized radar cross-section (NRCS) and wind speed estimates were also obtained from the Envisat RA-2 data, provided by GlobWave Project (http://globwave.ifremer.fr/). For $\mathrm{SWH}$, we used corrected values to take into account known biases in RA-2 measurements at low wave heights $(<2.5 \mathrm{~m})$. SARAL-AltiKa data were obtained from AVISO (http://www.aviso.altimetry.fr/). Envisat data are available for the period 2002-2012. AltiKa altimeter onboard SARAL satellite was launched February 25th, 2013. We used AltiKa data for 2013 only.

AltiKa is the first satellite altimeter operating in Ka-band and a particular wind speed model is needed to translate the radar cross section $\left(\sigma_{0}\right)$ measurements to surface wind speed estimates. Here, we used the empirical relationship derived by Lillibridge et al. (2014) which is available on the AVISO products. While, long waves are certainly known to impact nadir ocean backscatter measurements (e.g., Tran et al. 2007; Vandemark et al. 2004; Gourrion et al. 2002), this provides a $\sigma_{0}$-wind speed model to obtain first guess reasonable values of the local wind speed. 


\section{Wind waves in ice-free zones}

\subsection{Ka- and Ku-band sensitivity}

The "sensitivity" of Ka-band AltiKa and Ku-band Envisat RA-2 measurements to significant wave height (SWH) at different wind speeds can first be analyzed for our particular wind sea cases. Figure 2 shows SWH versus inverse NRCS, $\sigma_{0}$, measured by Ka- and Ku-band altimeter. Following a classical approximation, the $\sigma_{0}$ is related to mean square slope (MSS) of the sea surface as

$\sigma_{0}=R^{2} / M S S$

where $R$ is an effective Fresnel reflection coefficient to possibly take into account small sea diffraction and curvature effects (Tran and Chapron 2006) and/or non-Gaussian correction (Chapron et al. 2000), and MSS is the so-called filtered mean squared slope parameter associated to the statistics of rough facets contributing to radar returns. Comparing scatter plots in Figures $2 \mathrm{a}$ and $2 \mathrm{~b}$ an apparent difference in the slope can be observed indicating that Ka-band $\sigma_{0}$ is apparently more sensitive than Ku-band $\sigma_{0}$ to SWH changes.

To further investigate this difference, we use the model roughness spectrum suggested by Yurovskaya et al. (2013) elaborated on experimental data. The practical MSS can be evaluated from omnidirectional wave saturation spectrum, $B_{0}$, as:

$$
M S S=\int_{0}^{k_{d}} B_{0} d \ln k
$$

where $k_{d}$ is an upper limit to specify the smallest quasi-specular facet size. This limit is linked to the radar wavenumber, $k_{r}$, as: $k_{d}=\alpha k_{r}$, with $\alpha<<1$. Correspondingly, SWH following the model spectrum reads 
$H_{s}=4 \times\left(\int_{0}^{\infty} k^{-2} B_{0} d \ln k\right)^{1 / 2}$,

which is dependent on the inverse wave age of the seas defined as $U_{10} / C_{p}$, where $U_{10}$ is wind speed at 10 meters height and $C_{p}$ is phase velocity of the dominant long wave. Calculations of the $H_{s}$ versus $\sigma_{0}$ based on equations (1-3) with constant Fresnel coefficient are evaluated for $50 \mathrm{~km}, 100 \mathrm{~km}$ and $200 \mathrm{~km}$ fetch, respectively, and shown on Figure 2. Here, we adjust the model results at the lowest values of $H_{s}$ (blue lines on Figure 2). As found, the model curves deviate from the data at the larger $H_{s}$., showing that observed slope of the data cannot be explained by dependence of the MSS (2) on radar frequency. This fact suggests the necessity to take into account the small scale roughness impact within quasi-specular facets, leading to modification of the effective Fresnel coefficient in (2). This modification for is dependent on the radar frequency (Elfouhaily et al. 1998; Kudryavtsev et al. 2005)

$R^{2}=R_{0}^{2} \exp \left(-4 k_{r}^{2} h_{s}^{2}\right)$

where $R_{0}$ is the nominal Fresnel coefficient, and $h_{s}^{2}$ is the variance of small roughness height in the wavenumber range $k>k_{d}$. Using this correction largely improves the model fit (red lines on Figure 2) to confirm the stronger dependence of $\sigma_{0}^{-1}$ on wind speed for Ka-band as compared to Ku-band measurements. This was already pointed out in the derivation of the AltiKa wind speed model in Lillibridge et al. (2014). The same conclusion was also discussed when comparing Ku- and C-band dual-frequency TOPEX data (Elfouhaily et al. 1998). In Ka-band, the small scale roughness is supported by capillary waves which are very sensitive to the wind speed, with wind exponent about 3 (Yurovskaya et al. 2013). For the Ku-band, not only the wavenumber is significantly smaller, but small scale roughness is also supported 
by capillary-gravity waves (in the vicinity of the minimum phase velocity) which are less dependent on wind speed, with wind exponent about 2.

\subsection{Dependence of Hs on ice free area}

Figure 3 shows an example plot of along-track measurements of wind speed and SWH in two ice-free zones with areas of $10^{6}$ and $2 \times 10^{4} \mathrm{~km}^{2}$, respectively. Using the AltiKa retrieved wind, SWH for fully developed seas are calculated using expression $g H_{s} / U_{10}^{2}=0.21$ (Pierson and Moskowitz 1964), where $g$ is acceleration due to gravity. While the local wind speed is somehow expected to be underestimated as the MSS parameter is lower than for fully developed seas (see Vandemark et al. 2005), the measured SWH are systematically smaller. This already illustrates the dependence of wind wave heights on spatial scale of icefree zone. This dependence is further discussed in the next section. While fetch implicitly depends on the size of the ice-free zone, it is also related to wind direction. However, we did not consider it as it would drastically reduce our present dataset. This may induce some discrepancies in our results, but shall not affect the overall analysis.

The dataset for the period 2002-2013 consists of 2152 sets of measurements from either Envisat RA-2 or AltiKa. Each set includes three parameters: area of an individual ice-free zone, mean values of SWH and wind speed from any altimeter track that crossed the corresponding zone. Further analysis was performed in terms of similarity theory of Kitaigorodskii (1962):

$$
\tilde{H}_{s}=f(\tilde{s}),
$$

where $\tilde{H}_{s} \equiv g H_{s} / U_{10}^{2}$ is dimensionless SWH, $\tilde{s}=g S^{1 / 2} / U_{10}^{2}$ is the dimensionless wave generation spatial scale based on area $S$ of ice-free zone, $f(x)$ is a universal function to be defined. 
On Figure 4 altimeter measurements are represented as dimensionless variables resulting from similarity theory (5). Though carrying large range of wave heights, wind speeds and areas, the data are effectively grouped when presented in terms of dimensionless energy, defined as $\tilde{\varepsilon}=\tilde{H}_{s}^{2} / 16$.

These measurements can thus be compared with known empirical relations of wind wave growth, which are typically expressed through dimensionless energy as:

$\tilde{\varepsilon}=a \tilde{x}^{b}$

where $\tilde{x}=g X / U_{10}^{2}$ is dimensionless fetch (corresponds to distance $X$ from coastline to point of measurement), $a$ and $b$ are coefficients yielding best fit to observations. Based on results of the Joint North Sea Wave Project (JONSWAP) Hasselmann et al. (1980) estimated $a$ and $b$ as $1.6 \times 10^{-7}$ and 1 , respectively. Donelan et al. (1985) suggested $a=8.4147 \times 10^{-7}$ and $b=0.759$ for their observations in Lake Ontario and in a large laboratory tank. Both these empirical relations are represented on Figure 4 along with dimensionless energy for fully developed seas derived from Pierson-Moskowitz spectrum (Pierson and Moskowitz 1964), and the relation proposed by Elfouhaily et al. (1997)

$\tilde{H}_{s}=0.26 \times\left(\tanh \left(\tilde{x} / \tilde{x}_{0}\right)^{0.4}\right)^{1.25} ; \tilde{x}_{0}=2.2 \times 10^{4}$,

to asymptotically coalesce results of previous studies of fetch-limited wave growth and wave height for fully developed seas. Note that JONSWAP (Hasselmann et al. 1980) and Donelan et al. (1985) relations represent field studies and are only valid for short fetches, therefore limited on Figure 4. In general, such fetches are shorter than covered by this study, despite relatively small ice-free zones analyzed here. Also note that for comparison with our data all empirical relations were averaged within fetch $X$, i.e. 
$\frac{1}{X} \int_{0}^{X} f(\tilde{x}) d \tilde{x}$

For pure wind sea conditions, altimeter data may also be used to estimate peak wavelengths. Both empirical relations for wave steepness $\beta=H_{s} K_{p} / 2$ (where $K_{p}$ is spectral peak wavenumber) and relations based on physical wind wave models (e.g., Badulin 2014; and references therein) may be used for this. Here we estimated the peak wavelength, $\lambda_{p}=2 \pi / K_{p}$, from $H_{s}$ measurements as $\lambda_{p}=4 \pi H_{s} / \beta$ using (7) and the empirical expression for dimensionless inverse-wave-age parameter $U_{10} / C_{p}$ from Elfouhaily et al. (1997):

$U_{10} / C_{p} \equiv U_{10} K_{p}^{1 / 2} / g^{1 / 2}=0.84 \times\left[\tanh \left(\tilde{x} / \tilde{x}_{0}\right)^{0.4}\right]^{-0.75}$,

where $\tilde{x}_{0}=2.2 \times 10^{4}$, Figure 5. All empirical relations averaged over available fetch $X$ are also plotted on Figure 5 along with the dimensionless peak wavelength for fully developed seas $g \lambda_{p} / U_{10}^{2}=2 \pi / 0.83^{2}$ (Pierson and Moskowitz 1964). Estimated wavelengths are in agreement with aforementioned relations on short fetches and may be regarded as their extrapolation on much longer fetches typical of open sea conditions.

\section{A case study}

A goal that remains of interest for altimeter wind retrieval is the detection and correction of wind speed errors associated with longer ocean waves that are not necessarily closely coupled to the local wind field. Evidence for a sea-state effect on altimeter-derived wind has been addressed in several studies (e.g., Gourrion et al. 2002). One central and possible unique factor using higher resolution and accurate $H_{s}$ estimates is to help better infer the spatial $H_{s}$ evolution. 
Indeed, known characteristics of wind wave growth suggest that long wave impacts can rapidly vary over fairly small spatial scales of order 10-100 km. As also reported, horizontal length scales for atmospheric fronts fall into this range as well. Based on our analysis, we can thus select cases corresponding to fetches of order 50-100 km for which a large $H_{s}$ gradient of order $1 \mathrm{~m}$ has been evaluated. Badulin (2014) proposed to estimate the significant steepness from measured $H_{s}$ variations. Correspondingly for such a gradient, i.e., $1 \mathrm{~m}$ for $100 \mathrm{~km}$, a significant steepness of about 0.0596 should be expected, much larger than the value 0.04 , generally corresponding to fully developed wind-wave conditions. Considering $H_{s}=1 \mathrm{~m}$, this higher steepness leads to a typical peak period of about $4 \mathrm{~s}$, and wavelength of about $30 \mathrm{~m}$. Using the JONSWAP fetch law, this shall then correspond to a wind speed of about $9 \mathrm{~m} / \mathrm{s}$, and a wave age $C_{p} / U=0.7$.

With a finer sensitivity to small $H_{s}$ values, the SARAL-AltiKa is thus ideally suited to check the possibility to infer the significant steepness from the $H_{s}$ variations over short fetches, to estimate an adjusted wind speed to be compared with the AltiKa wind product.

We analyze a case in Kara Sea on May $16^{\text {th }}, 2013$ with fetch less than $100 \mathrm{~km}$, Figure 6. Only six $1 \mathrm{~Hz}$ measurements spanning from 11:54:34 to 11:54:39 UTC are available in the selected area. Distance between two consecutive measurements equals to $7 \mathrm{~km}$, this corresponds to 35 $\mathrm{km}$ distance between first and last measurement. Over this interval $H_{s}$ grows from 0.72 to 1.1 m. This can also explain the decrease in $\sigma_{0}$ (not shown), leading to an increasing wind speed obtained using standard Ka-band $\sigma_{0}$ - wind speed model (from 5.74 to $8.25 \mathrm{~m} / \mathrm{s}$ ). However, supposing waves to simply develop due to increasing fetch for a fixed wind, we derived a wind speed of about $8.5 \mathrm{~m} / \mathrm{s}$ by fitting equation (7) to the data, assuming that first measurement corresponds to $25 \mathrm{~km}$ fetch.. To gain more insight into short spatial scale wave 
development and to assess AltiKa improved resolution capabilities, we also plot corresponding $40 \mathrm{~Hz}$ measurements, which, obviously, appear too noisy (unlike $40 \mathrm{~Hz} \sigma_{0}$ measurements). We thus remove outliers with $H_{s}$ lower than $0.3 \mathrm{~m}$ and then average the data in $0.2 \mathrm{sec}$ time window (equivalent to $5 \mathrm{~Hz}$ measurements or $1.4 \mathrm{~km}$ spatial resolution), Figure 6 . These data demonstrate short scale variability of wind wave inside localized icefree area. In general, measured wave heights are apparently consistent with empirical relations, proving AltiKa maximum wind speed to be the most adequate. NCEP/NCAR reanalysis further supports this estimating wind speed over the selected area for 12:00 UTC as $8.2 \mathrm{~m} / \mathrm{s}$.

\section{Summary and Conclusions}

We analyzed wind waves in three Arctic seas in 2002-2013 using altimeter data. Swell influence was best eliminated by analyzing only open water zones fully enclosed by ice. Initial data were analyzed in terms of similarity theory for developing wind waves (Kitaigorodskii 1962). Dependencies of dimensionless significant wave height and wavelength on dimensionless wave generation spatial scale were compared to known empirical dependencies for fetch-limited wind wave development. Within small ice-free zones, they are in a reasonable agreement. With increasing open water area, altimeter data appear as extrapolation of empirical dependencies on longer fetches including fully developed seas condition. The results of this study may be used to estimate wind wave characteristics under the conditions of decreasing Arctic sea ice extent due to climate change.

We also discuss the new possibilities AltiKa opens to infer corrections of wind speed errors associated with longer ocean waves and sea state degree of development. With improved sensitivity, new analysis can be performed to study in more detail the wave growth, and over limited open water areas, we recommend to consider the largest derived wind speed value to 
estimate the local mean wind. Future studies shall be more particularly focused on exploiting these new high resolution capabilities of the SARAL-AltiKa measurements in closed-basins to further help analyze wind wave growth parameters.

\section{Acknowledgements}

This research was funded by the Mega-grant of the Russian Federation Government to support scientific research under the supervision of leading scientist at RSHU, No. 11.G34.31.0078. The authors also acknowledge support by RFBR (project 14-05-91760/14) and the Ministry of Science and Education (government assignment 5.2483.2014/K), and are grateful to NSIDC, GlobWave and AVISO for provided data.

\section{References}

Asplin, M. G., R. Galley, D. G. Barber, and S. Prinsenberg. 2012. "Fracture of summer perennial sea ice by ocean swell as a result of Arctic storms." Journal of Geophysical Research: Oceans (1978-2012) 117, no. C6.

Badulin, S. I. 2014. “A Physical Model of Sea Wave Period from Altimeter Data.” Journal of Geophysical Research: Oceans 119 (2): 856-69. doi:10.1002/2013JC009336.

Chapron, B., V. Kerbaol, D. Vandemark, and T. Elfouhaily. 2000. "Importance of peakedness in sea surface slope measurements and applications." Journal of Geophysical Research 105, no. C7: 17195-17202.

Comiso, J. C., C. L. Parkinson, R. Gersten, and L. Stock. 2008. “Accelerated Decline in the Arctic Sea Ice Cover." Geophysical Research Letters 35 (1): L01703. doi:10.1029/2007GL031972. 
Donelan, M. A., J. Hamilton, and W. H. Hui. 1985. "Directional Spectra of Wind-Generated Waves." Philosophical Transactions of the Royal Society A: Mathematical, Physical and Engineering Sciences 315 (1534): 509-62. doi:10.1098/rsta.1985.0054.

Elfouhaily, T., B. Chapron, K. Katsaros, and D. Vandemark. 1997. “A Unified Directional Spectrum for Long and Short Wind-Driven Waves." Journal of Geophysical Research 102 (C7): 15781-96. doi:10.1029/97JC00467.

Elfouhaily, T., D. Vandemark, J. Gourrion, and B. Chapron. "Estimation of wind stress using dual-frequency TOPEX data." Journal of Geophysical Research: Oceans (1978-2012) 103, no. C11 (1998): 25101-25108.

Gourrion, J., D. Vandemark, S. Bailey, B. Chapron, G. P. Gommenginger, P. G. Challenor, and M. A. Srokosz. 2002. "A two-parameter wind speed algorithm for Ku-band altimeters." Journal of atmospheric and oceanic technology 19, no. 12: 2030-2048.

Hasselmann, D. E., M. Dunckel, and J. A. Ewing. 1980. "Directional wave spectra observed during JONSWAP 1973." Journal of physical oceanography 10, no. 8: 1264-1280.

Kitaigorodskii, S. A. "Applications of the theory of similarity to the analysis of windgenerated wave motion as a stochastic process." Izv.Geophys. Ser. Acad. Sci., USSR 1 (1962): 105-117.

Kudryavtsev, V., D. Akimov, J. Johannessen, and B. Chapron. 2005. “On Radar Imaging of Current Features: 1. Model and Comparison with Observations." Journal of Geophysical Research 110 (C7): C07016. doi:10.1029/2004JC002505.

Lillibridge, J., R. Scharroo, S. Abdalla, and D. Vandemark. 2014. "One- and TwoDimensional Wind Speed Models for Ka-Band Altimetry." Journal of Atmospheric and Oceanic Technology 31 (3): 630-38. doi:10.1175/JTECH-D-13-00167.1. 
Parkinson, C. L., and J. C. Comiso. 2013. "On the 2012 Record Low Arctic Sea Ice Cover: Combined Impact of Preconditioning and an August Storm." Geophysical Research Letters 40 (7): 1356-61. doi:10.1002/grl.50349.

Pierson, W. J., and L. Moskowitz.1964. "A proposed spectral form for fully developed wind seas based on the similarity theory of SA Kitaigorodskii." Journal of Geophysical Research $69(24): 5181-5190$.

Tran, N., and B. Chapron. 2006. "Combined wind vector and sea state impact on ocean nadirviewing Ku-and C-band radar cross-sections." Sensors 6, no. 3: 193-207.

Tran, N., B. Chapron, and D. Vandemark. 2007. "Effect of long waves on Ku-band ocean radar backscatter at low incidence angles using TRMM and altimeter data." Geoscience and Remote Sensing Letters, IEEE 4, no. 4: 542-546.

Vandemark, D., B. Chapron, J. Sun, G. H. Crescenti, and H. C. Graber. 2004. "Ocean wave slope observations using radar backscatter and laser altimeters." Journal of physical oceanography 34 , no. $12: 2825-2842$.

Verron, J., P. Sengenes, J. Lambin, J. Noubel, N. Steunou, A. Guillot, N. Picot, S. CoutinFaye, R. Gairola, D.V.A. Raghava Murthy, J. Richman, D. Griffin, A. Pascual, F. Rémy, P. A. Gupta, 2014. “The SARAL/AltiKa altimetry satellite mission.” Marine Geodesy

Yurovskaya, M. V., V. A.Dulov, B. Chapron, and V. N. Kudryavtsev. 2013. "Directional Short Wind Wave Spectra Derived from the Sea Surface Photography." Journal of Geophysical Research: Oceans 118 (9): 4380-94. doi:10.1002/jgrc.20296. 


\section{Figures}

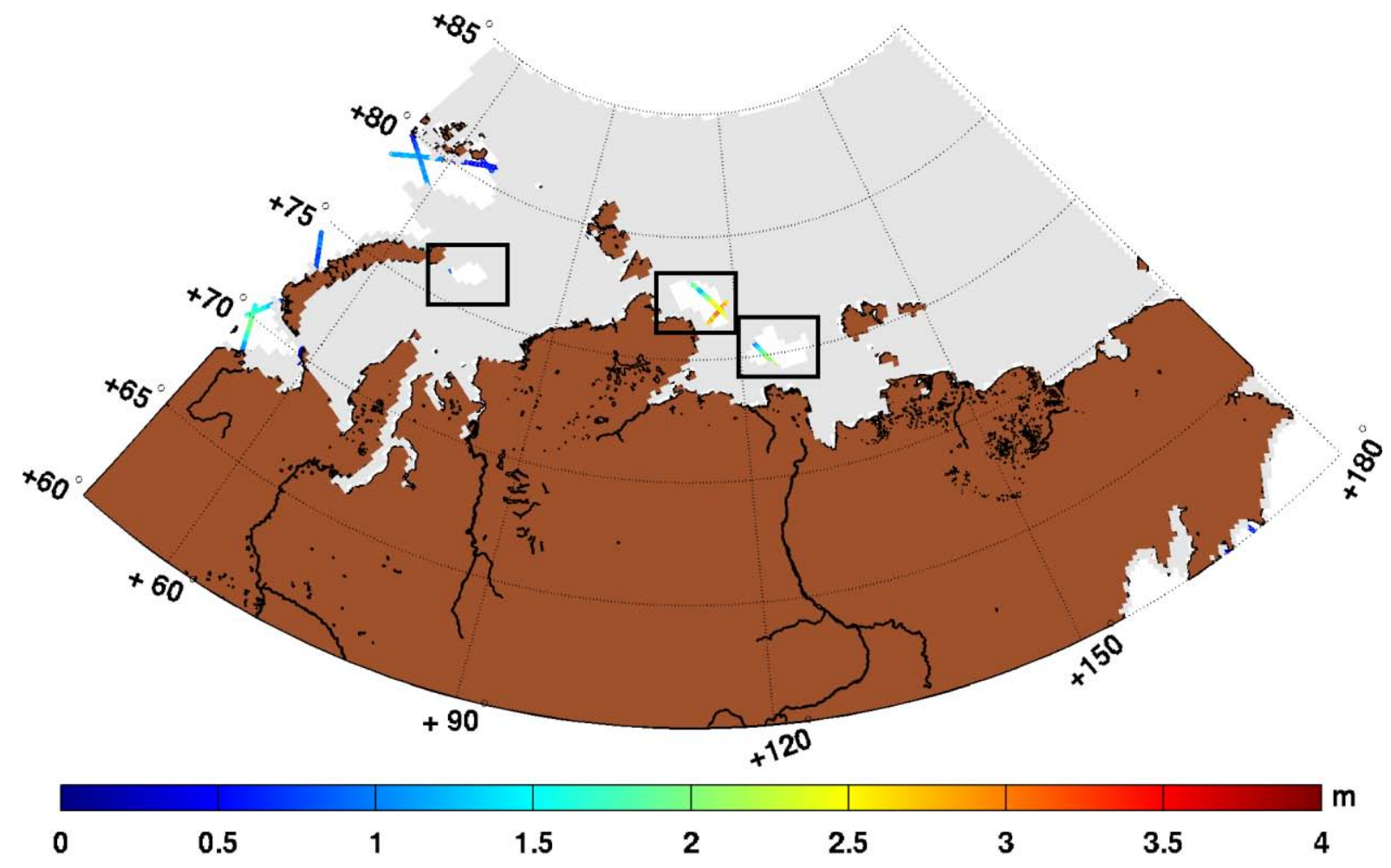

Figure 1. An example of the area of interest for June $18^{\text {th }}$, 2013. Isolated ice-free zones are marked. Light gray indicates ice cover (ice concentration more than $1 \%$ ). AltiKa significant wave heights are plotted. 

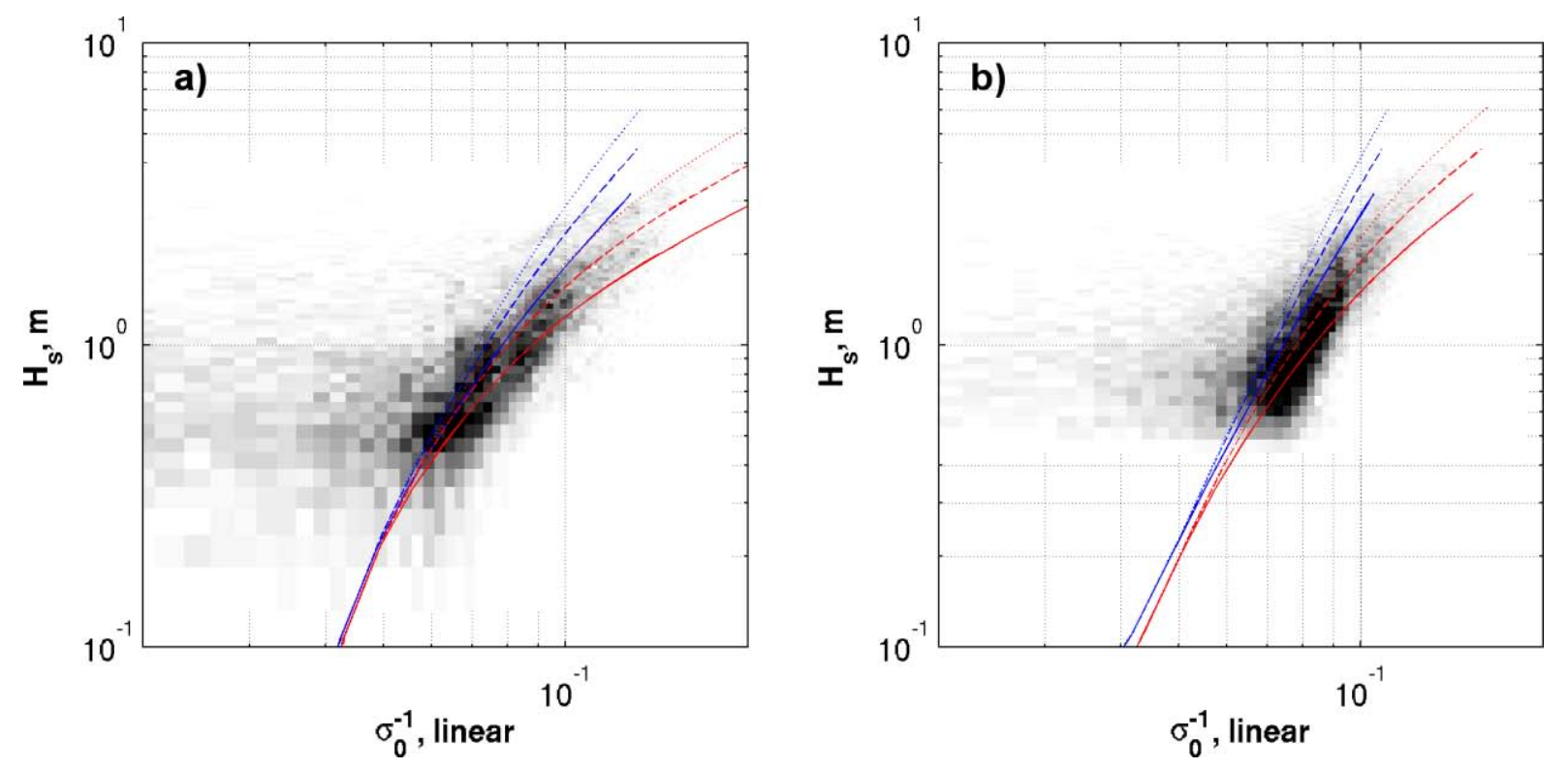

Figure 2. Comparison of a) Ka-band and b) Ku-band altimeter sensitivity. Blue lines obtained from equations (1-3) using constant Fresnel reflection coefficient, red lines obtained after modification (4) of the Fresnel coefficient. Solid, dashed and dotted lines represent fetches of 50, 100 and $200 \mathrm{~km}$, respectively. 

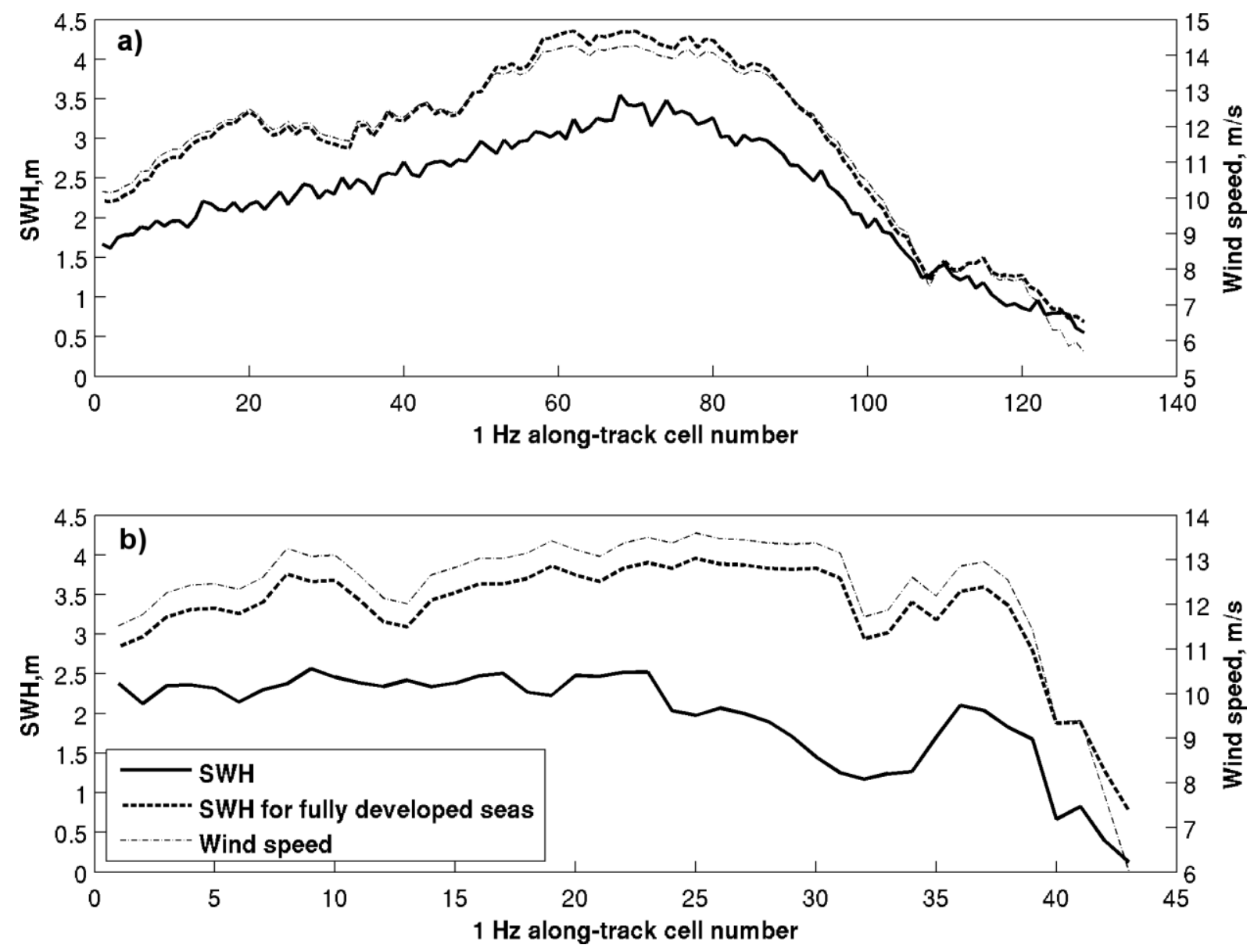

Figure3. An example of plot of along-track altimeter measurements in ice-free zone with area of a) $10^{6} \mathrm{~km}^{2}$; b) $2 \times 10^{4} \mathrm{~km}^{2}$. Solid line shows measured significant wave height, dashed line denotes significant wave height for fully developed seas, dotted line indicates wind speed (right vertical axis). 


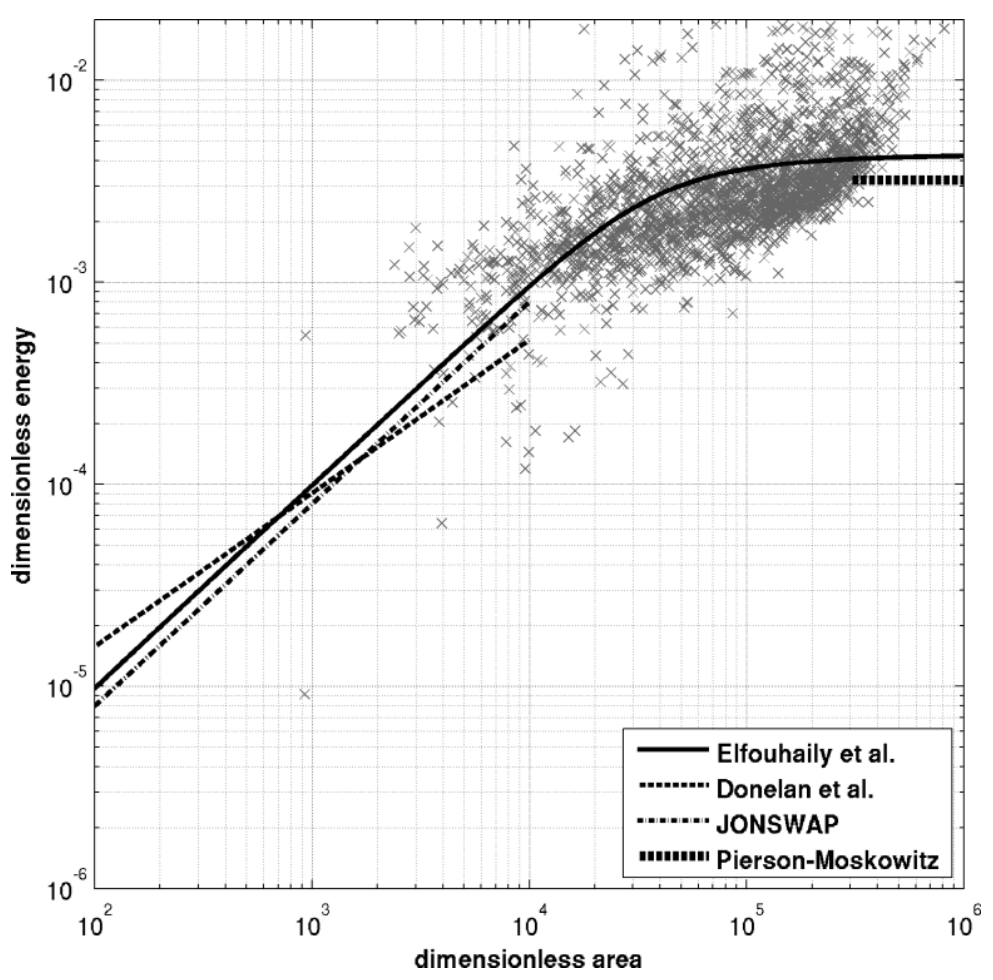

Figure 4. Dependence of dimensionless energy on dimensionless area. Crosses correspond to altimetry data. 


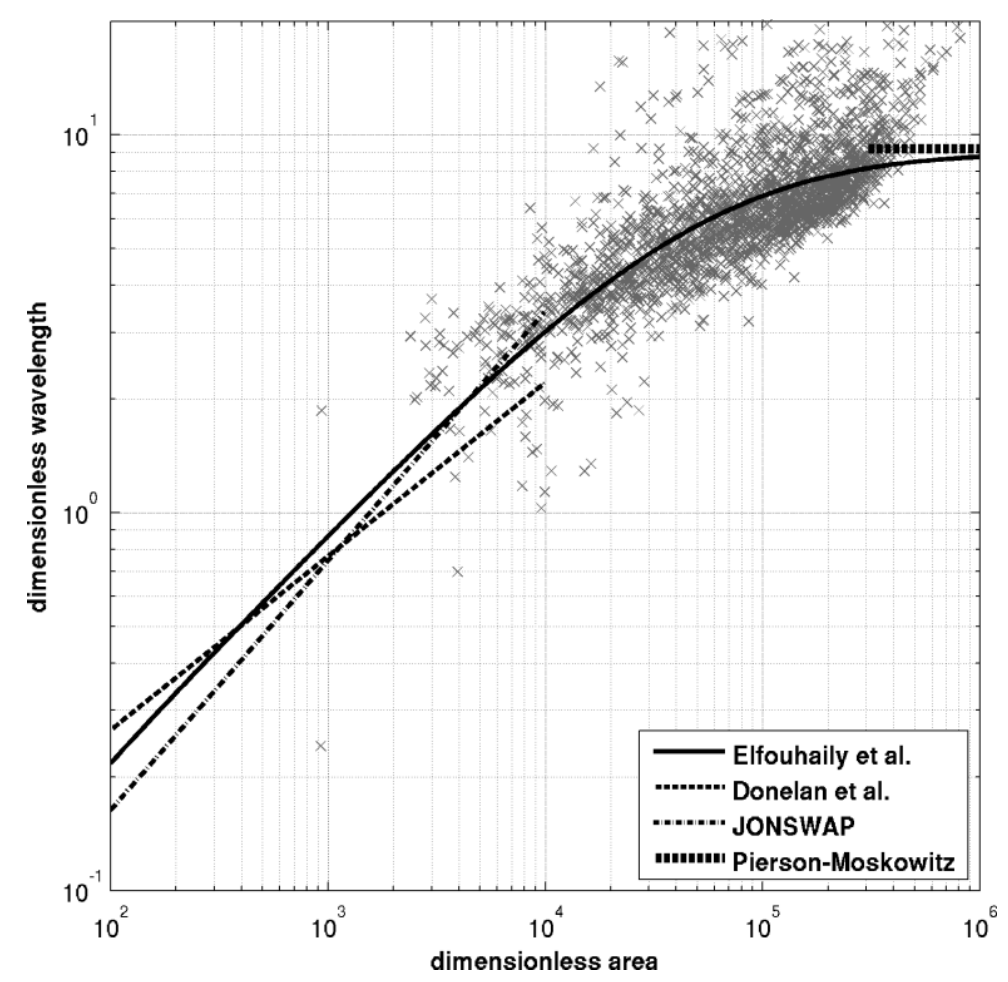

Figure 5. Dependence of dimensionless wavelength on dimensionless area. Crosses correspond to altimetry data. 


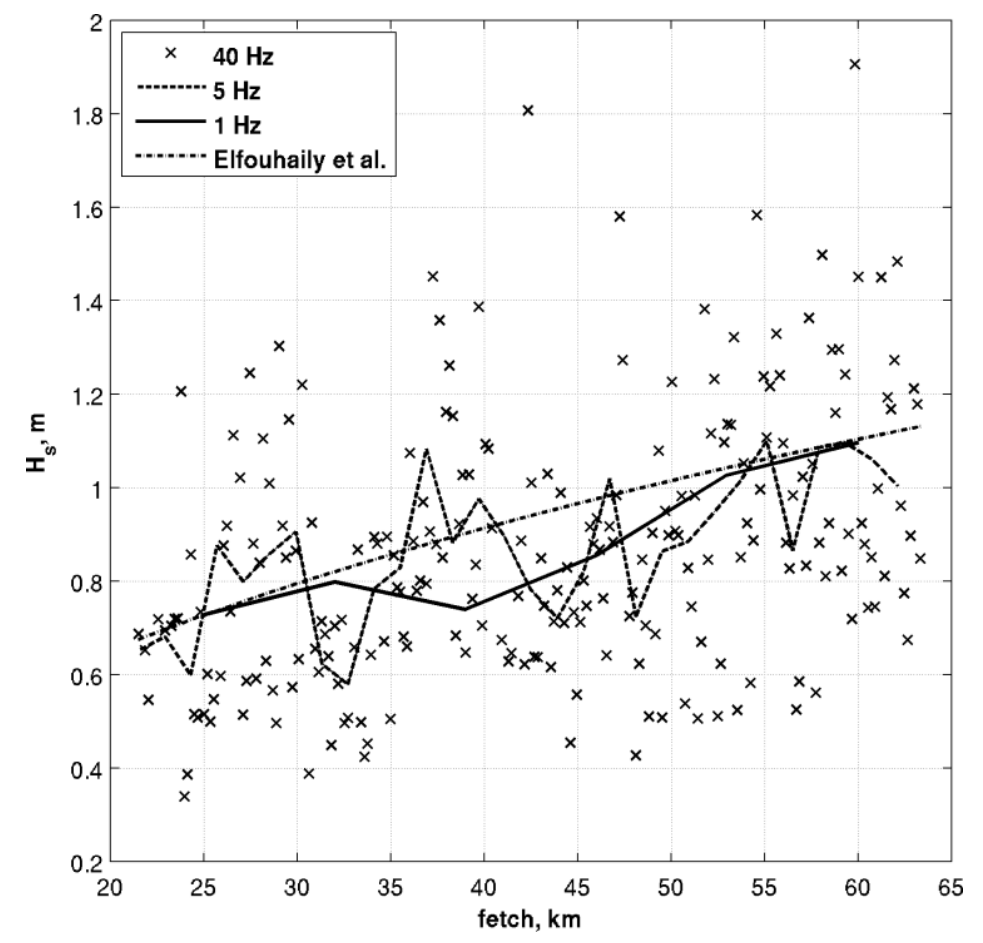

Figure 6. Example of AltiKa measurements at limited fetch from 11:54:34 UTC May $16^{\text {th }}, 2013$. Empirical SWH predicted by (7) for $8.25 \mathrm{~m} / \mathrm{s}$ wind speed is shown by dash-dotted line. 